\title{
ANALISIS PENGARUH CASH POSITION, DEBT TO EQUITY RATIO, DAN RETURN ON ASSETS TERHADAP DIVIDEN PAYOUT RATIO PADA PERUSAHAAN- PERUSAHAAN YAN TERDAFTAR DI BURSA EFEK INDONESIA PERIODE 2012 - 2014
}

\author{
Annisa Trilestari \\ annisatrilestari6@gmail.com \\ Universitas Ahmad Dahlan \\ Desta Rizky Kusuma \\ kusuma.desta@gmail.com \\ Universitas Ahmad Dahlan
}

\begin{abstract}
ABSTRAK
This research was conducted to examine the effect of variable cash sition, debt to equity ratio, and return on assets on dividen payout ratio on compnies listed on the Indonesian Stock Exchane 2012 - 2015 periode. The population in research is all companies listed on the Indonesian Stock Exchange 2012 - 2015 periode. The number of samples used for a many as 59 companies with used purposive sampling. Data obtained from the publication of Indonesian Capital Market Directory (ICMD). The analysis technique used data penel regression and hypothesis testing using the $\mathrm{t}$ statistik and koefisien determination with the 5\% level if confidence.The results showed that the cash position has a significant effect on the dividen payout ratio with a positive direction. While the debt to equity ratio has a significant effect on the dividen payout ratio with a negative direction. Meanwhile, the return on assets have no significant effect on the dividen payout ratio. Based on a statistical analysis of significance of $t$ cash position values obtained 0,0233 (less than 0,05) and values significance for debt to equity ratio obtained 0,0007 (less than 0,05 ). While return on assets have a significance values obtained 0,5209 (than 0,05 ), so it can be concluded that variable cash position and debt to equity ratio have a significant influence on dividen payout ratio. While return on assets have no significance influnce on dividen payout ratio. From Adjusted $\mathrm{R}^{2}$ value of 0,054332 indicates that there are independent variable in the model can explain influence on dividen payout ratio by $5,43 \%$, while $94,57 \%$ residual explain bay the dividen payout ratio of other variables outside the model.
\end{abstract}

Keyword: Cash Position; Debt to Equity Rati; Return On Assets; Dividen Payout Ratio.

\section{PENDAHULUAN}

Perkembangan ekonomi suatu negara dapat diukur dengan banyak cara, salah satunya dengan mengetahui tingkat perkembangan dunia pasar modal dan industri industri sekuritas pada negara tersebut. Dalam aktivitas di pasar modal, para investor memiliki harapan dari investasi yang ditanamkannya, yaitu berupa capital gain dan dividen. Kebijakan pembayaran dividen mempunyai pengaruh
}

bagi pemegang saham dan perusahaan yang membayar dividen. Kebijakan dividen (dividen policy) adalah keputusan apakah laba yang diperoleh perusahaan akan dibagikan kepada pemegang saham sebagai dividen, atau akan ditahan dalam bentuk laba ditahan guna pembiayaan investasi dimasa mendatang (Sartono, 2010).

Kebijakan pembayaran dividen mempunyai pengaruh bagi pemegang saham dan perusahaan yang membayar 
dividen. Kebijakan dividen perusahaan tergambar pada dividend payout rationya yaitu persentase laba yang dibagikan dalam bentuk dividen tunai, artinya besar kecilnya dividend payout ratio akan mempengaruhi keputusaan investasi para pemegang saham dan disisi lain berpengaruh pada kondisi keuangan perusahaan.

Rasio pembayaran dividend atau dividend payout ratio (DPR) pada intinya merupakan persentase dari laba setelah pajak yang dibagikan kepada pemegang saham yang merupakan perbandingan antara dividend per share (DPS) dengan earning per share (EPS). Rasio pembayaran dividend (dividend payout ratio) merupakan rasio untuk menentukan jumlah laba yang dibagi dalam bentuk dividen kas dan laba ditahan sebagai sumber pendanaan.Rasio pembayaran dividen dapat dihitung dengan membagi dividen kas tahunan dengan laba tahunan atau dividen per lembar saham dibagi laba per lembar saham.Rasio ini menunjukkan persentase laba perusahaan yang dibayarkan kepada pemegang saham dalam bentuk kas (Van Horne, 198 dalam Asakdiyah, 2007). Cash position $(C P)$ atau likuiditas dari suatu perusahaan merupakan faktor penting yang harus dipertimbangkan sebelum mengambil keputusan untuk menetapkan besarnya dividen yang akan dibayarkan kepada para pemegang saham. Oleh karena dividen merupakan cash outflow, maka semakin kuatnya cash position atau likuiditas perusahaan berarti semakin besar juga kemampuan perusahaan membayar dividen (Riyanto, 2001).

Debt to equity rasio yaitu rasio yang digunakan untuk menilai perusahaan dalam meminjam uang untuk melakukan kegiatan operasi dan investasi. Debt to equity ratio (DER) merupakan rasio hutang terhadap modal. Rasio ini mengukur seberapa jauh perusahaan dibiayai oleh hutang, dimana semakin tinggi nilai rasio ini menggambarkan gejala yang kurang baik bagi perusahaan (Sartono, 2001).
Return on assets adalah rasio perbandingan antara net income dengan total assets. Return on assets menunjukkan kemampuan perusahaan dalam menghasilkan laba dengan assets yang dimiliki pada masa lalu, kemudian dianalisis untuk memproyeksikan kemampuan perusahaan dalam menghasilkan laba dimasa mendatang. Semakin tinggi keuntungan yang diterima perusahaan, maka berpengaruh pada tingginya ketersedian kasa/dana perusahaan yang dialokasikan untuk dividen.

Penelitian terhadap faktor - faktor yang mempengaruhi kebijakan pembagian dividen payout ratio (DPR) sudah banyak yang dilakukan. Adriani, (2017) dalam skripsinya yang berjudul " Pengaruh Debt To Equity Ratio, Cash Position, Investment Opportunity Set, Firm Size dan Return On Assets Terhadap di Vidend Payout Ratio pada Perusahaan Manufaktur yang Terdaftar di Bursa Efek Indonesia". Hasil penelitian ini menunjukkan bahwa Variabel Debt to Equity Ratio, Cash Position, Return On Assets berpengaruh positif tidak signifikan terhadap Dividend Payout Ratio, variabel Investment Opportunity Set berpengaruh positif dan signifikan terhadap Dividen Payout Ratio.

Marlina dan Danica (2009) yang berjudul "Analisis Pengaruh Cash Position, Debt to Equity Ratio, Return On Assets Terhadap Dividend Payout Ratio". Hasil penelitian menunjukkan bahwa variabel Cash Position (CP) dan Return On Assets (ROA) mempunyai pengaruh positif terhadap Dividend Payout Ratio, sedangkan Debt to Equity Ratio (DER) tidak mempunyai pengaruh yang signifikan terhadap Dividend Payout Ratio. Firm Size berpengaruh negatif tidak signifikan terhadap Dividen Payout Ratio.

Basuki (2012), yang meneliti tentang "Analisis Pengaruh Cash Ratio, Debt To Total Assets Ratio, Debt To Equity Ratio, Return On Assets dan Net Profit Margin Terhadap Dividen Payout Ratio Pada Perusahaan Otomotif yang 
Listing di Bursa Efek Indonesia Periode 2007-2011". Hasil penelitian ini menunjukkan bahwa variabel $C R, D A R$, $D E R$ dan $R O A$ secara parsial tidak signifikan terhadap DPR pada level of significance lebih dari $5 \%$. Namun $C R$ dan $R O A$ berpengaruh positif sedang $D A R$ dan $D E R$ berpengaruh negatif. Variabel NPM terbukti berpengaruh positif dan signifikan terhadap $D P R$. Sedangkan secara bersamasama $(C R, D A R, D E R, R O A$, dan NPM) terbukti signifikan berpengaruh terhadap $D P R$ pada level kurang dari $5 \%$

\section{Rumusan Masalah}

Berdasarkan uraian identifikasi masalah yang telah dikemukakan di atas, maka dapat diperoleh rumusan masalah sebagai berikut :

1. Apakah Cash Position berpengaruh positif terhadap Dividen Payout Ratio pada perusahaan yang terdaftar di Bursa Efek Indonesia?

2. Apakah Debt to Equity Ratio berpengaruh negatif terhadap Dividen Payout Ratio pada perusahaan yang terdaftar di Bursa Efek Indonesia?

3. Apakah Return on Assets berpengarah positif terhadap Dividen Payout Ratio pada perusahaan yang terdaftar di Bursa Efek Indonesia?

\section{REVIEW LITERATUR DAN HIPOTESIS}

\section{Landasan Teori \\ Kebijakan Dividen}

Kebijakan dividend merupakan keputusan perusahaan untuk membagikan keuntungan yang diperoleh perusahaan kepada para pemegang saham sesuai dengan yang diharapkan. Kebijakan deviden merupakan bagian yang tidak dapat dipisahkan dengan keputusan pendanaan perusahaan.

\section{Dividend Payout Ratio (DPR)}

Dividend payout ratio adalah sebuah parameter untuk mengukur besarnya dividen yang akan dibagikan ke pemegang saham. Dividen payout ratio adalah perbandingan antara dividend per share dengan earning per share pada periode yang bersangkutan. Di dalam kompenen dividen per share terkandung unsur dividen, dimana semakin tinggi nilai dividen yang dibagikan maka semakin tinggi juga dividen payout rationya, hal tersebut sangat menarik bagi investor. Pembagian dividen yang terlalu besar bukan tidak diinginkan oleh investor, akan tetapi menjaga agar tidak terjadi kesulitan likuiditas perusahaan diwaktu mendatang. Di sisi lain apabila pembagian dividen lebih kecil dari harapan investor, maka akan dikhawatirkan terjadinya pelepasan saham oleh investor dari perusahaan tersebut.

\section{Cash Position (CP)}

Posisi kas atau likuiditas dari suatu perusahaan merupakan faktor yang sangat penting yang harus dipertimbangkan sebelum mengambil keputusan untuk menetapkan besarnya dividen yang akan dibayarkan kepada para pemegang saham. Oleh karena dividen merupakan cash outflow, maka semakin kuatnya posisi kas atau likuiditas perusahaan, maka semakin besar kemampuan perusahaan membayar dividen (Riyanto, 2001). Posisi kas yang besar merupakan kekuatan bagi suatu perusahaan, hal tersebut disebabkan karena kas sangat dibutuhkan oleh perusahaan untuk pembiayaan operasional. Posisi kas yang tinggi atau baik akan menunjukkan kinerja perusahaan yang baik juga. Bagi perusahaan yang memiliki posisi kas yang semakin kuat akan semakin besar kemampuannya dalam membayar dividend. Dengan semakin meningkatnya posisi kas dapat meningkatkan keyakinan para investor untuk membayar dividen yang diharapkan oleh investor. Dengan semakin meningkatnya posisi kas juga dapat 
meningkatkan keyakinan para investor untuk membayra dividen tunai (cash dividend) yang diharapkan oleh investor. Cash dalam persamaan menunjukkan besarnya kas yang tercermin dalam neraca (sisi aset/current asset). Sedangkan current liabilllity menunjukkan jumlah kewajiban jangka pendek perusahaan yang tercermin dalam neraca (sisi liability/current liability).

\section{Debt To Equity Ratio (DER)}

Debt to equity ratio merupakan rasio hutang terhadap modal. Rasio ini mengukur seberapa jauh perusahaan dibiayai oleh hutang., dimana semakin tinggi nilai rasio ini menggambarkan gejala yang kurang baik bagi perusahaan (Sartono, 2001: 66). Peningkatan utang pada gilirannya akan mempengaruhi besar kecilnya laba bersih yang tersedia bagi para pemegang saham termmasuk dividen yang diterima karena kewajiban untuk membayar utang lebih diutamakan daripada pembagian dividen. Dalam rangka mengukur risiko, fokus perhatian kreditor jangka panjang terutama ditujukkan pada prospek laba dan perkiraan arus kas. Meskipun demikian, mereka tidak dapat । mengabaikan pentingnya tetap mempertahankan keseimbangan antar proporsi aktiva yang didanai oleh kreditur dan yang didanai oleh pemilik perusahaan. Debt to Equity ratio mengukur keseimbangan proporsi antara aktiva yang didanai oleh kreditor dan yang didanai oleh pemilik perusahaan dan juga dapat memberikan gambaran mengenai struktur modal yang dimiliki oleh perusahaan, sehingga dapat dilihat tingkat risiko tak tertagihnya suatu utang.

\section{Return On Assets (ROA)}

Return On Assets adalah analisis untuk mengukur kemampuan perusahaan menghasilkan laba dengan menggunakan total asset (kekayaan) yang dipunyai perusahaan setelah disesuaikan dengan biaya - biaya untuk mendanai asset tersebut. Variasi dalam perhitungan $R O A$ bisa dengan memasukkan biaya pendanaan. Biaya - biaya pendanaan yang dimaksud adalah bunga yang merupakan biaya pendanaan dengan hutang (Hanafi dan Halim, 2005). Ratio ini mengukur tingkat kembalian investasi yang telah dilakukan oleh perusahaan dengan menggunakan seluruh aktiva yang dimilikinya. Ratio ini dapat diperbandingkan dengan tingkat bunga bank yang berlaku (Prastowo, 2011). Keuntungan yang layak dibagikan para pemegang saham adalah keuntungan setelah perusahaan memenuhi seluruh kewajiban tetapnya yaitu beban pajak. Oleh karena itu, dividen diambil dari keuntungan bersih yang berhasil diperoleh perusahaan, keuntungan tersebut akan mempengaruhi besarnya Dividend Payout Ratio yang dibagikan perusahaan.

\section{Penelitian Terdahulu}

Dari beberapa hasil penelitian yang relevan mendukung teori yang dikemukakan diatas, maka berikut adalah beberapa penelitian terdahulu diantaranya yaitu, penelitian yang dilakukan Basuki (2012), yang meneliti tentang “ Analisis Pengaruh Cash Ratio, Debt To Total Assets Ratio, Debt To Equity Ratio, Return On Assets dan Net Profit Margin Terhadap Dividen Payout Ratio Pada Perusahaan Otomotif yang Listing di Bursa Efek Indonesia Periode 2007-2011". Hasil penelitian ini menunjukkan bahwa variabel $C R, D A R, D E R$ dan $R O A$ secara parsial tidak signifikan terhadap DPR pada level of significance lebih dari 5\%. Namun $C R$ dan $R O A$ berpengaruh positif sedang $D A R$ dan DER berpengaruh negatif. Variabel NPM terbukti berpengaruh positif dan signifikan terhadap $D P R$. Sedangkan secara bersama-sama $(C R$, $D A R, \quad D E R, \quad R O A$, dan NPM) terbukti signifikan berpengaruh terhadap $D P R$ pada level kurang dari $5 \%$. Penelitian lain yang dilakukan oleh

Putra (2017), yang meneliti tentang "Analisis Pengaruh Free Cash Flow, Asset 
Growth, Market To Book Value, Profitability dan Debt To Equity Ratio Terhadap Dividen Payout Ratio (Studi pada Perusahaan yang Tergabung dalam Indeks LQ- 45 Di Bursa Efek Indonesia Periode 2011-2015)". Hasil penelitian ini menunjukkan bahwa variabel - variabel independen secara simultan (uji F) berpengaruh terhadap Dividend Payout Ratio dengan tingkat signifikansi 0,000. Sedangkan secara parsial (uji t) menunjukkan bahwa variabel Free Cash Flow dan Return On Assets mempunyai pengaruh positif dan signifikan terhadap Dividend Payout Ratio. Variabel Assets Growth dan Debt to Equity Ratio mempunyai pengaruh negatif dan signifikan terhadap Dividend Payout Ratio. Variabel Market to Book Value mempunyai pengaruh negatif dan tidak signifikan terhadap Dividend Payout Ratio. Nilai adjusted R2 sebesar 0,458 yang berarti bahwa kemampuan kelima variabel independen dapat menjelaskan Dividend Payout Ratio sebesar 45,8\%, sedangkan sisanya dijelaskan oleh faktor lain. Selanjutnya adalah penelitian yang dilakukan oleh Adriani, (2017) dalam skripsinya yang berjudul “ Pengaruh Debt To Equity Ratio, Cash Position, Investment Opportunity Set, Firm Size dan Return On Assets Terhadap di Vidend Payout Ratio pada Perusahaan Manufaktur yang Terdaftar di Bursa Efek Indonesia”. Hasil penelitian ini menunjukkan bahwa Variabel Debt to Equity Ratio, Cash Position, Return On Assets berpengaruh positif tidak signifikan terhadap Dividend Payout Ratio, variabel Investment Opportunity Set berpengaruh positif dan signifikan terhadap Dividen Payout Ratio, Firm Size berpengaruh negatif tidak signifikan terhadap Dividen Payout Ratio.

Selanjutnya adalah penelitian yang dilakukan oleh Jurnal Marlina dan Danica (2009) yang berjudul "Analisis Pengaruh Cash Position, Debt to Equity Ratio,
Return On Assets Terhadap Dividend Payout Ratio". Hasil penelitian menunjukkan bahwa variabel Cash Position (CP) dan Return On Assets (ROA) mempunyai pengaruh positif terhadap Dividend Payout Ratio, sedangkan Debt to Equity Ratio (DER) tidak mempunyai pengaruh yang signifikan terhadap Dividend Payout Ratio.

\section{Hipotesis}

H1: Cash Position (CP) berpengaruh positif terhadap Dividen Payout Ratio (DPR).

H2: Debt to Equity berpengaruh negatif terhadap Dividen Payout Ratio.

H3: Return On Assets berpengaruh positif terhadap Dividen Payout Ratio

\section{METODE PENELITIAN}

\section{Populasi dan Sampel}

Populasi dalam penelitian ini adalah perusahaan perusahaan yang terdaftar di Bursa Efek Indonesia (BEI)yang didapat dari sumber www.idx.co.id.

Sampel adalah bagian dari jumlah dan karakteristik yang dimiliki oleh populasi tersebut. Penarikan sampel dalam penelitian ini adalah perusahaan yang terdaftar di Bursa Efek Indonesia (BEI) dengan kriteria yang telah ditentukan.Sampel dalam penelitian ini adalah sebagian perusahaan yang terdaftar di Bursa Efek Indonesia sebanyak 59 perusahaan. Pengambilan sampel dalam penelitian ini menggunakan purposive sampling.

\section{Definisi Operasional}

1. Variabel Independen

\section{Cash Position (X1)}

Posisi kas atau likuiditas dari suat perusahaan adalah rasio kas akhir tahun.

$$
\text { Cash Position }=\frac{\text { saldo } \text { kas akhir }}{\text { laba bersih setelah pajak }} \times 100 \%
$$


Debt To Equity Ratio (X2)

Debt To Equity Ratio merupakan rasio utang terhadap modal.

Debt To Equity Ratio $=\frac{\text { total nutang }}{\text { total modal sendiri }} \times 100 \%$

\section{Return On Asset Ratio (X3)}

Return On Assets merupakan variabel yang menjadi indikator perusahaan dalam kemampuan menghasilkan keuntungan. Return On Asset $=\frac{\text { laba bersin sebelum pa jak }}{\text { total aktiva }} \times 100 \%$

\section{Variabel Dependen}

\section{Dividen Payout Ratio (DPR)} mencerminkan kemampuan perusahaan untuk melakukan pembayaran dividen kepada setiap pemegang saham.

Dividen Payout Ratio $=\frac{\text { dividen } \text { kas per lembar saham }}{\text { laba yang diperoleh per lembar saham }} \times 100 \%$

\section{Teknik Analisis Data}

1. Stastistik Deskriftif

Menurut Sugiyono (2015:) statistika deskriptif adalah statistik yang digunakan untuk menganalisis data dengan cara mendeskripsikan atau menggambarkan data yang telah terkumpul sebagaimana adanya tanpa bermaksud membuat kesimpulan yang berlaku untuk umum atau generalisasi.

2. Uji Asumsi Klasik

a. Uji Normalitas

Kususma dan Ismanto (2012: 27) pada program eviews uji normalitas dapat menggunakan uji Jarque - Bera untuk menguji normalitas. Jarque - Bera adalah uji statistik untuk mengetahui data tersebut besdistribusi normal atau tidak pengambilan keputusan pada uji Jarque Bera adalah bila nilai nilai prob. J-B lebih besar dari $\alpha 5 \%$ (prob. J-B > 0,05), maka data tersebut berdistribusi normal.

\section{b. Uji Autokorelasi}

Kusuma dan Ismanto (2012: 47) multikolinearitas adalah salah satu masalah dalam analisis regresi dengan OLS, yang berarti terdapat korelasi atau hubungan yang sangat tinggi diantara variabel independen. Multikolineritas hanya terjadipada regresi pada regresi majemuk yang melibatkan beberapa variabel independen sehingga tidak terjadi pada regresi sederhana.

\section{c. Uji Heteroskedastisitas}

Untuk mendeteksi ada tidaknya heteroskedastisitas adalah dengan menggunakan Uji White. Uji ini dilakukan dengan meregresikan residual kuadrat sebagai variabel dependen dengan variabel dependen ditambah dengan kuadrat variabel. Pengambilan keputusan dengan menggunakan program eviws 9 adalah sebagai berikut:

Prob. Chi square (p-value) $>0,05(\alpha)$ : tidak terjadi heteroskedastisitas.

Prob. Chi square (p-value) $<0,05(\alpha)$ : terjadi heteroskedastisitas.

\section{d. Uji Multikolinearitas}

Kusuma dan Ismanto (2012: 33) autokorelasi merupakan hubungan antara residual satu observasi dengan observasi lainnya. Setiap data residual pada satu observasi diharapkan saling bebas dengan lainnya atau tidak ada autokorelasi. Pemeriksaan akan dugaan adanya autokorelasi dapat dilakukan dengan menggunakan uji Breusch - Godfrey. Uji B - $\mathrm{G}$ atau uji LM (Lagrange Multiplier) pengambilan keputusannya adalah sebagai berikut:

a. Prob. Chi Square $>0,05=$ Tidak ada autokorelasi

b. Prob. Chi Square $<0,05=$ Terjadi autokorelasi

\section{Analisis Regresi Data Panel}

Dalam menentukkan model pemilihan estimasi dalam regresi data panel yang harus dilakukan adalah dengan meregresikan data panel dengan menggunakan metode common effect dan fixed effect. Kemudian melakukan uji chow untuk menentukkan metode yang digunakan antara common effect dan fixed 
effect, dengan perbandingan sebagai berikut:

a. Prob. Chi Square $<0,05=$ fixed effect.

b. Prob. Chi Square $>0,05=$ common effect.

Apabila berdasarkan perbandingan tersebut hasil keputusannya adalah menerima common effect maka model yang digunakan adalah dengan OLS. Sedangkan apabila hasil keputusannya adalah menerima fixed effect maka dilanjutkan dengan melakukan uji Haustman untuk menentukan metode yang akan digunakan antara metode fixed effect atau random effect dengan perbandingan sebagai berikut :

a. Prob. Cross Section Random $<0,05=$ fixed effect

b. Prob. Cross Section Random > 0,05 = random effect.

Adapun model regresi data panel yang digunakan sebagai berikut:

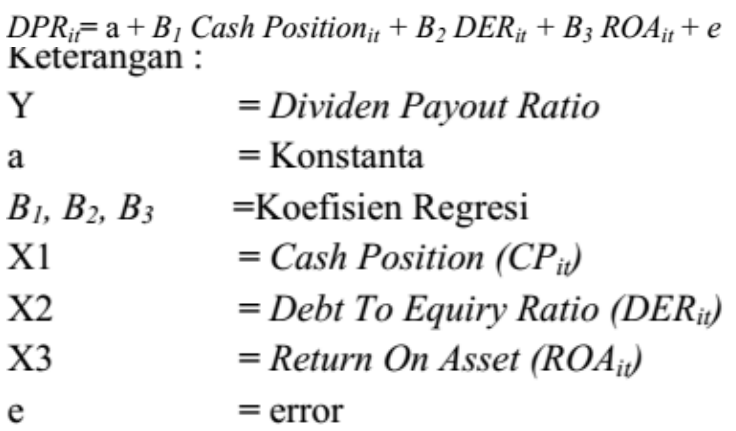

\section{Uji Hipotesis}

1. Uji Parsial (Uji T)

Untuk menguji pengaruh variabel independen terhadap dividend payout ratio secara parsial ( untuk menguji signifikan atau tidaknya masing-masing variabel bebas terhadap dividend payout ratio) dengan menggunakan taraf signifikansi 0,05 (5\%).

\section{Uji Koefisien Determinasi}

Uji Koefisien Determinasi digunakan untuk menguji seberapa besar kemampuan model dalam menerangkan variasi dependen. Nilai koefisien determinasi menunjukkan persentase variasi nilai variabel dependen yang dapat dijelaskan oleh persamaan regresi yang dihasilkan.

\section{HASIL PENELITIAN DAN PEMBAHASAN}

\section{Hasil Statistik Deskriptif}

\begin{tabular}{|l|c|c|c|c|}
\hline \multicolumn{5}{|c|}{ Hasil Statistik Uji Deskriptif } \\
\hline Mean & DPR $\%$ & CP\% & DER $\%$ & ROA $\%$ \\
\hline Median & 32,25 & 76,74 & 128,04 & 10,30 \\
\hline Maximum & 32,70 & 84,28 & 100,60 & 7,10 \\
\hline Minimum & 68,85 & 131,60 & 492,74 & 65,72 \\
\hline Std. Dev & 0,07 & 0,64 & 11,32 & $-0,29$ \\
\hline Sumber : Data Sekunder 2017 & 15,61 & 32,02 & 96,87 & 9,83 \\
\hline
\end{tabular}

\section{Hasil Uji Asumsi Klasik}

1. Uji Normalitas

\begin{tabular}{|c|c|c|c|c|}
\hline Independen & Dependen & $\begin{array}{c}\text { Nilai Prob. } \\
\text { JB }\end{array}$ & Alpha & Kesimpulan \\
\hline \multirow{3}{*}{ DPR } & CP & \multirow{2}{*}{0,841416} & 0,05 & Normal \\
\cline { 2 - 3 } & DER & & \\
\cline { 2 - 2 } & ROA & & & \\
\hline
\end{tabular}

Berdasarkan hasil residual test Jarque-Berra yang digunakan untuk menguji normalitas residual didapatkan bahwa residual pada semua regresi yang digunakan yang telah dilakukan perbaikan sehingga hasilnya berdistribusi normal dan ini memenuhi asumsi normalitas.

2. Uji Autokolerasi

\begin{tabular}{|c|c|c|c|c|}
\hline Independen & Dependen & $\begin{array}{c}\text { Nilai Prob. } \\
\text { Chi Square }\end{array}$ & Alpha & Kesimpulan \\
\hline \multirow{2}{*}{ DPR } & CP & \multirow{2}{*}{0,0000} & 0,05 & $\begin{array}{c}\text { Terjadi } \\
\text { Autokorelasi }\end{array}$ \\
\cline { 2 - 2 } & DER & & \\
\cline { 2 - 2 } & ROA & & \\
\hline \multicolumn{2}{|c|}{ Sumber : Olah Data Eviews 9, 2017}
\end{tabular}

Pada pengujian autokorelasi data yang diteliti memiliki masalah autokorelasi. Oleh karena itu, untuk mengatasi masalah ini pada model panel dilakukan dengan penyembuhan dengan metode weighting dan dengan penguatan robusnest dari standard error coef covariance white period sehingga model menjadi layak digunakan untuk interpretasi data (Widarjono, 2009)

3. Uji Heteroskedastisitas

\begin{tabular}{|c|c|c|c|c|}
\hline Independen & Dependen & $\begin{array}{c}\text { Nilai Prob. Chi } \\
\text { Square }\end{array}$ & Alpha & Kesimpulan \\
\hline \multirow{3}{*}{ DPR } & CP & \multirow{2}{*}{0,7193} & 0,05 & $\begin{array}{c}\text { Tidak Terjadi } \\
\text { Heteroskedastisitas }\end{array}$ \\
\cline { 2 - 2 } & DER & 0,2017 & \\
\cline { 2 - 2 } & ROA & &
\end{tabular}


Berdasarkan hasil pengujian heteroskedastisitas, data yang diteliti tidakt terkena masalah heteroskedastisitas. Hal ini terlihat dari nilai prob. Ch-Square sebesar 0,7193 > 0,05 . Dengan demikian data dapat langsung diinterpretasikan tanpa menggunakan metode penyembuhan.

4. Uji Multikolineritas

\begin{tabular}{|c|c|c|c|}
\hline & CP & DER & ROA \\
\hline CP & 1,000000 & 0,154277 & -0.461557 \\
\hline DER & 0,154277 & 1,000000 & -0.341366 \\
\hline ROA & $-0,461557$ & $-0,341366$ & 1,000000 \\
iumber : olah data Eviews 9.2017 \\
Uji
\end{tabular} $\begin{gathered}\text { multikolinearitas } \\
\text { dilakukan }\end{gathered}$

dilakukan menggunakan metode korelasi antar variabel independen yaitu $C P, D E R, R O A$. Untuk menguji korelasi antara variabel independen digunakan pembanding untuk mengetahuinya yaitu dengan membandingkan nilai korelasi dengan 0,90 atau $<90 \%$ (Kusuma dan Ismanto, 2012). Terlihat pada tabel 4.6 nilai korelasi antar variabel independen $C P, D E R, R O A<90 \%$ atau 0,90 maka menunjukkan tidak adanya gejala multikolinearitas. Uji multikolinearitas antara $C P$ dengan $D E R$ sebesar 0,154277 , sehingga dapat diambil disimpulkan bahwa antara $C P$ dan $D E R$ tidak terjadi multikolinearitas. Begitupun dengan variabel $D E R$ dengan $R O A$ yang mempunyai nilai sebesar 0,341366 juga menghasilkan kesimpulan yang sama, yaitu tidak terjadi multikolinearitas dan uji multikolinearitas antara $R O A$ dengan $C P$ yang mempunyai nilai sebesar 0,461557 juga menghasilkan kesimpulan yang sama, yaitu tidak terjadi multikolinearitas.

\section{Uji Regresi Data Panel}

\begin{tabular}{|c|c|c|c|}
\hline Variabel & Coefficient & t-statistik & Prob. \\
\hline $\mathrm{C}$ & 31,70703 & 8,637840 & 0,0000 \\
\hline $\mathrm{CP}$ & 0,065292 & 2,283466 & 0,0233 \\
\hline DER & $-0,041634$ & $-3,438591$ & 0,0007 \\
\hline ROA & 0,083635 & 0,642900 & 0,5209 \\
\hline Prob (F-Statistik) & \multicolumn{3}{|c|}{0,004912} \\
\hline R-Squared & \multicolumn{3}{|c|}{0,054332} \\
\hline \multicolumn{4}{|c|}{$\begin{array}{l}\text { Sumber: Hasil Olah Data Eviews } 9,2017 \\
\text { 3entuk persamaa regresi panel dengan model random effect adalah sebagai berik }\end{array}$} \\
\hline \multicolumn{4}{|c|}{$D P R_{i t}=\alpha+B_{l} C P_{i t}+B_{2} D E R_{i t}+B_{3} R O A_{3}+e_{i t}$} \\
\hline \multicolumn{4}{|c|}{$D P R_{i t}=31,70703+0,065292 C P_{i t}-0,041634 D E R_{i t}+0,083635 R O A_{i t}+\mathrm{e}_{i t}$} \\
\hline
\end{tabular}

1. Hipotesis 1 Cash Position berpengaruh positif terhadap Dividen Payout Ratio.

Hasil dari penelitian ini memperlihatkan bahwa nilai Cash Position > 0, yaitu sebesar 0,065292 > 0 , yang berarti Cash Position berpengaruh positif terhadap Dividen Payout Ratio, sedangkan Prob. $\mathrm{t}<(\alpha$ : $0,05)$ yaitu sebesar0,0233 $<0,05$ yang berarti bahwa Cash Position memiliki pengaruh positif yang signifikan terhadap Dividen Payout Ratio. Maka H1 diterima, dengan demikian cash position berpengaruh positif terhadap dividen payout ratio.

2. Hipotesis 2 Debt to Equity Ratio berpengaruh negatif terhadap Dividen Payout Ratio.

Hasil dari penelitian ini memperlihatkan bahwa nilai Debt to Equity Ratio < 0, yaitu sebesar $0,041634<0$, yang berarti bahwa Debt to Equity Ratio berpengaruh negatif terhadap Dividen Payout Ratio, sedangkan Prob. $\mathrm{t}<(\alpha: 0,05)$ yaitu sebesar $0,0007<0,05$ yang berarti bahwa Debt to Equity Ratio memiliki pengaruh negatif yang signifikan terhadap Dividen Payout Ratio. Maka $\mathrm{H} 2$ diterima, dengan demikian debt to equity ratio berpengaruh negatif siginifikan terhadap dividen payout ratio.

3. Hipotesis 3 Return On Assets berpengaruh positif terhadap Dividen Payout Ratio

Hasil dari penelitian ini memperlihatkan bahwa nilai Return On Asset > 0, yaitu sebesar 0,083635>0, yang berarti bahwa Return On Asset berpengaruh positif terhadap Dividen Payout Ratio, sedangkan Prob. $\mathrm{t}<(\alpha$ : $0,05)$ yaitu sebesar $0,5209<0,05$ yang berarti bahwa Return On Asset tidak berpengaruh signifikan terhadap Dividen Payout Ratio. Maka H3 diterima, dengan demikian return on assets berpengaruh positif tetapi tidak signifikan terhadap dividen payout ratio. 
5. Hasil Uji Koefisien Determinasi

Berdasarkan tabel 4.7 diatas nilai $\mathrm{R} 2=0,054332$ yang menunjukkan kemampuan model. Variabel CP, DER, ROA mampu menjelaskan pengaruhnya sebesar 5,43\% terhadap variabel DPR, sedangkan $94,57 \%$ sisanya dipengaruhi oleh variabel lain.

\section{Pembahasan}

a. Pembuktian Hipotesis 1 (Pengaruh Cash Position terhadap Dividen Payout Ratio)

Hipotesis 1 menduga bahwa Cash Position berpengaruh positif terhadap Dividen Payout Ratio (DPR) dan hasil penelitian menunjukkan bahwa hipotesis 1 terdukung, dimana Cash Position berpengaruh positif terhadap Dividen Payout Ratio (DPR). Hal ini mengindikasikan bahwa perusahaan yang memiliki posisi kas yang semakin kuat berarti memiliki kemampuan membayar dividen yang tinggi juga. Dividen merupakan cash outflow yang tentu saja memerlukan posisi cash yang kuat sehingga perusahaan mampu membayar dividen.

b. Pembuktian Hipotesis 2 (Pengaruh Debt to Equity Ratio terhadap Dividen Payout Ratio)

Hipotesis 2 menduga bahwa Debt to Equity Ratio berpengaruh negatif terhadap Dividen Payout Ratio (DPR) dan hasil penelitian menunjukkan bahwa hipotesis 2 terdukung, dimana Debt to Equity Ratio berpengaruh negatif terhadap Dividen Payout Ratio (DPR). Hal ini mengidikasikan bahwa semakin tinggi nilai Debt to Equity Ratio menggambarkan gejala yang kurang baik bagi perusahaan, karena rasio ini mengukur seberapa jauh perusahaan dibiayai oleh hutang (Sartono,2001). Semakin besar tingkat Debt to Equity Ratio, berarti komposisi utang juga semakin tinggi, sehingga akan berakibat pada semakin rendahnya kemampuan untuk membayar dividen.
Setiap kenaikan Debt to Equity Ratio akan menurunkan kemampuan kemampuan perusahaan untuk membayar dividen kepada para pemegang saham.

c. Pembuktian Hipotesis 3 (Pengaruh Return On Asset terhadap Dividen Payout Ratio)

Hipotesis 3 menduga bahwa Return On Assets (ROA) berpengaruh positif terhadap Dividen Payout Ratio (DPR) dan hasil penelitian menunjukkan bahwa hipotesis 3 tidak terdukung, dimana Return On Asset tidak berpengaruh terhadap Dividen Payout Ratio. Hal ini mengindikasikan bahwa tidak selamanya Return On Asset mempengaruhi pembayaran dividen, karena ternyata semakin meningkatnya Return On Asset belum tentu akan meningkatkan Dividen Payout Ratio. Perusahaan akan terus menahan sebagian besar laba atau pendapatannya untuk ditanamkan didalam perusahaan. Dengan demikian dana yang tersedia akan lebih besar dan hal ini akan mempercepat pertumbuhan perusahaan.

\section{KESIMPULAN DAN SARAN}

\section{Kesimpulan}

Berdasarkan penelitian yang dilakukan mengenai analisis pengaruh Cash Position, Debt to Equity Ratio dan Return On Assets terhadap Dividen Payout Ratio pada Perusahaan - perusahaan yang terdaftar di Bursa Efek Indonesia selama periode 2012 - 2015, maka dapat disimpulkan bahwa:

1. Cash Position (CP) berpengaruh positif terhadap Dividen Payout Ratio (DPR).

2. Debt to Equity Ratio (DER) berpengaruh negatif terhadap Dividen Payout Ratio (DPR).

3. Return On Asset (ROA) tidak berpengaruh terhadap Dividen Payout Ratio (DPR). 


\section{Saran}

Berikut beberapa saran yang dapat diberikan kepada pihak yang terkait dalam penelitian ini :

a. Bagi penelitian selanjutnya, agar lebih memperhatikan waktu dan sampel penelitian, waktu dan sampel penelitian yang banyak atau besar kemungkinan akan memperoleh hasil yang lebih baik.

b. Peneliti selanjutnya agar menambah variabel penelitian yang benar - benar relevan terhadap Dividen Payout Ratio.

c. Manajemen perlu lebih jeli lagi dalam mempertimbangkan hal - hal yang berkaitan dengan kebijakan deviden, karena kepentingan perusahaan dan investor ditentukan disini. Evaluasi kinerja perusahaan perlu diperdalam lagi agar tercipta kebijakan deviden yang optimal.

d. Bagi investor atau calon investor dapat menjadikan variabel Cash Position (CP), Debt to Equity Ratio (DER), dan Return On Assets (ROA) sebagai variabel - variabel yang dipertimbangkan dalam menetapkan investasinya apabila dividen menjadi salah satu unsur yang diprioritaskan dalam berinvestasi.

\section{DAFTAR PUSTAKA}

Andriani, Queen Mulya. 2017. “ Pengaruh Debt To Equity Ratio, Cash Position, Investment Opportunity Set, Firm Size dan Return On Assets Terhadap Dividen Payout Ratio pada Perusahaan Manufaktur yang Tertdaftar di Bursa Efek Indonesia”. Yogyakarta. Universitas Sarjanawiyata Tamansiswa.

Anil, Kanwal, and Kapoor, Sujana. 2008. "Determinants of Divident Payout Ratio Study of Indian Information Technology Sector". International Research Journal of Finance and Economics - Issue 15. Hlm. 63 - 71. Asakdiyah, Salamatun. 2007. Manajemen Keuangan II : " Alat Analisis dan
Aplikasi”. Yogyakarta. Universitas Ahmad Dahlan.

Astiti, Yuniarta dan Sujana. 2017. "Pengaruh Debt To Equity Ratio, Current Ratio, Net Present Margin, Return On Assets Terhadap Dividend Payout Ratio Studi padaPerusahaan Basic Industry dan Properti, Real Estate dan Building Contruktion yang Terdaftar di Bursa Efek Indonesia Periode 2011 2015". Singaraja. Universitas Pendidikan Ganesha.

Basuki, Arief. 2012. "Analisis Pengaruh Cash Ratio, Debt To Total Equity Ratio, Return On Assets dan Net Profit Margin Terhadap Dividend Payout Ratio pada Perusahaan Otomotif yang Listing di Bursa Efek Indonesia Periode 2007 - 2011”. Semarang. Universitas Diponegoro.

Chasanah, Amalia Nur. 2008. "Faktor Faktor yang Mempengaruhi Dividend Payout Ratio pada Perusahaan yang Listed di Bursa Efek Indonesia". Semarang. ThesisUniversitas Diponegoro.

Ghozali, Imam. 2011. "Aplikasi Analisis Multivariate Dengan Program SPSS". Semarang.

Hanafi, Mamduh. "Manajemen Keuangan". (Yogyakarta: BPFE, 2004). Hlm. 361.

Hanafi dan Halim. 2005. "Analisis Laporan Keuangan”. Yogyakarta. UPP AMP YKPN.

Hermuningsih, Sri. "Pengantar Pasar Modal Indonesia”. Yogyakarta. UPT STIM YKPN. HIm. 2.

Http://www.idx.co.id/id/id/beranda/publik asi/ringkasankinerjaperusahaantercat 
at.aspx diakses pada tanggal diakses pada tanggal 30 Novemberr 2017.

Https://www.sahamok.com/emiten/sektoraneka-industri/sub-sektor-otomotifkomponen/. Diakses pada tanggal 15 November 2017

Kuncoro, Mudrajad. 2013. "Metode Riset (Untuk Bisnis dan Ekonomi)". Yogyakarta. Universitas Gadjah Mada.

Kusuma dan Ismanto. 2012 "Modul Praktikum Eviews". Yogyakarta. Universitas Ahmad Dahlan.

Margaretha, Farah. 2005. "Teori dan Aplikasi Manajemen Keuangan : Investasi dan Sumber Dana Jangka Panjang”. (Jakarta: PT Gramedia Widiasarana Indonesia, 2005). Hlm. 142-144.

Marietta, Unzu. 2013. “Analisis Pengaruh Cash Ratio, Return On Assets, Growth, Firm Size, Debt To Equity Ratio Terhadap Dividen Payout Ratio : Studi pada Perusahaan Manufaktur yang Terdaftar di Bursa Efek Indonesia Tahun 2008 - 2011”. Semarang. Universitas Diponegoro.

Marlina, Lisa. dan Danica, Clara. 2009. "Analisis Pengaruh Cash Position, Debt to Equity Ratio, dan Return On Assets Terhadap Dividen Payout Ratio". Jurnal Manajemen Bisnis, Volume 2, Nomer 1.

Maulida Priyo, Estika dan Sampurno R. Djoko. 2013. "Aalisis Pengaruh Return On Asset, Debt To Equity Ratio, Firm Size, Growth dan Free Cash Flow Terhadap Dividen Payout Ratio (Studi Empirisnpada Perusahaan Manufaktur yang Terdaftar di BEI Periode 2008 2011)”. Semarang. Universitas Diponegoro.
Nadjibah. 2008. "Analisis Pengaruh Assets Growth, Size, Cash Ratio dan Return On Assets". Semarang. Thesis Universitas Diponegoro.

Prastowo, Dwi. 2011. Analisis Laporan Keuangan "Konsep dan Aplikasi". Edisi Ketiga. Yogyakarta. UPP STIM YKPN. Hlm. $79-81$.

Pribadi, Anggit Satria dan Sampurno R. Djoko. 2012. " Analisis Pengaruh Cash Position, Firm Size, Growth Opportunity, Ownership dan Return On Assets Terhadap Dividen Payout Ratio". Jurnal Manajemen Vol. 1.Putra, Oktommy. 2017. "Analisis Pengaruh Free Cash Flow, Market to Book Value, Profotability (ROA), Debt to Equity Ratio Terhadap Dividen Payout Ratio : Studi pada Perusahaan yang Tergabung dalam Indeks LQ 45 di Bursa Efek Indonesia Periode 2011 - 2015". Semarang. Universitas Diponegoro.

Riyanto, Bambang. 2001. "Dasar Dasar Pembelajaran Perusahaan". Yogyakarta, BPFE. Hlm. 265.

Sartono, Agus. 2001. Manajemen Keuangan "Teori dan Aplikasi". Edisi Keempat. Yogyakarta. BPFE. Hlm. $66-67$.

Sugiyono. 2015. " Metode Penelitian Kuantitatif, Kualitatif dan R\&D”. Bandung. Ikatan Penerbit Indonesia (IKAPI).

Swastyatu, Made Wiradharma. 2014. "Analisis Faktor Faktor yang Mempengaruhi Kebijakan Dividen Payout Ratio yang Terdaftar di Bursa Efek Indonesia”. E- jurnal S1 Ak. Universitas Pendidikan Ganesha. Volume 2, Nomer 1. Van Horne dan Wachowicz. 2014. "Prinsip Prinsip Manajemen 
Keuangan". Edisi keTigabelas.

Jakarta. Salemba Empat. Hlm. 213.

Widarjono. 2009. "Ekonometrika

Pengantar dan Aplikasinya".

Yogyakarta. Universitas Islam

Indonesia. 